\title{
Validation of a Spanish-Language Scale for Evaluating Perceived Quality of Care of Medical Abortions Before 9 Weeks Gestation
}

\section{Rosa Cabedo-Ferreiro}

Institut Universitari d'Investigació en Atenció Primària Jordi Gol

Maria-Mercedes Vicente-Hernández

Institut Universitari d'Investigació en Atenció Primària Jordi Gol

Josep-Maria Manresa-Domínguez

Universitat Autonoma de Barcelona

\section{Miriam Gómez-Masvidal}

Institut Universitari d'Investigació en Atenció Primària Jordi Gol

Laura Montero-Pons ( $\square$ Imontero.ics@gencat.cat)

Institut Universitari d'Investigació en Atenció Primària Jordi Gol

\section{Azahara Reyes-Lacalle}

Institut Universitari d'Investigació en Atenció Primària Jordi Gol

\section{Gemma Falguera-Puig}

Institut Català de la Salut

\section{Research Article}

Keywords: Service quality, medical abortion, induced abortion, satisfaction, healthcare quality, validation studies

Posted Date: November 29th, 2021

DOI: https://doi.org/10.21203/rs.3.rs-1067866/v1

License: (c) (1) This work is licensed under a Creative Commons Attribution 4.0 International License. Read Full License 


\section{Abstract}

Background: Spanish Organic Law 2/2010 legalizes abortion within 14 weeks of gestation. Medical abortion with mifepristone and misoprostol is around $97 \%$ effective and is offered at primary care centers during the first 9 weeks of gestation. It consists administration of $200 \mathrm{mg}$ of mifepristone by healthcare professional and of the self-administration $800 \mathrm{mg}$ of misoprostol by the patient at home, along with prescribed analgesics. However, the quality of this process as perceived by patients has never been assessed. This study aims to validate a scale designed to assess the perceived quality of this process.

Methods: Validation study of a Spanish adaptation of the SERVPERF scale. In total, 289 patients completed a self-administered questionnaire consisting of 26 items previously evaluated by a group of experts. A re-test was performed on 53 of these patients 15 days later to assess interobserver consistency.

Results: The non-response rate did not exceed $2.1 \%$. The floor effect was $26 \%$ and the ceiling effect did not surpass $83 \%$. The linearly weighted Kappa coefficient was good to excellent, in general. An exploratory factor analysis was performed with varimax rotation, obtaining a total of 7 dimensions that explain $65.9 \%$ of the variability. The internal consistency (Cronbach's alpha) for all items was 0.862 .

Conclusion: This psychometric instrument is valid and reliable for assessing the quality of care of medical abortion.

Medical abortion is efficient, effective and eliminates the need for hospital care, anesthesia and surgical risk. However, user satisfaction has yet to be determined. This study offers a validated scale to assess perceived quality of care, their quality experience and person-centered care for abortion as a fundamental part of overall service quality as a fundamental part of overall service quality.

\section{Introduction}

In Spain, there were 95,917 abortions in 2018, which represents a rate of $11.12 \%$ of women of reproductive age. In our sphere of influence, the Barcelona North Metropolitan Area, 1,995 medical abortions (MA) were performed, of which $90 \%$ were complete expulsions and $3 \%$ required curettage $[1,2]$.

Abortion within 14 weeks gestation (WG) was legalized under Spanish Organic Law 2/2010 on Sexual and Reproductive Health and Abortions[3]. It is offered at the Sexual and Reproductive Health Care Centers (ASSIR) of the Primary Care (PC) service. This guarantees continuity of care and proximity to the population, as recommended by the World Health Organization (WHO) [4]. MA is carried out before 9 WG. It consists of the selfadministration of $200 \mathrm{mg}$ of mifepristone and $800 \mathrm{mg}$ of misoprostol by the patient at home, along with prescribed analgesics. Patient progress is monitored and effective contraceptive counseling is provided as well[4]. 
MA have significantly changed sexual and reproductive health care, resulting in the creation of specific visits aimed at interrupting women's daily life as little as possible. The process has very high efficiency rates $(99.7 \%)$ [5].

In recent decades, health organizations have worked towards continuous quality improvement, not just by evaluating the quality of processes, safety and results, but also taking into account patients, their service quality experience and perceived satisfaction[6].

In this regard, there are two quality improvement plans in place in Catalonia: a plan for the management of excellence and safety (Health Plan for Catalonia 2016-2020)[7] and a satisfaction survey plan (PLAENSAC) [6]. However, no data has been collected on the quality of the MA process.

Many studies have evaluated health services from the angle of perceived quality of care [8]. To this end, quantitative quality measurement tools have been created, includingthe SERVQUAL $[9,10]$ and SERVPERF (SERVice-PERFormance) scales, which are based on customer perception. The SERVPERF survey comprises 22 perceptions items divided into 5 quality dimensions. While this scale has been used to evaluate commercial services [11-14], it is also suitable for use healthcare, having been employed to assess public health in Malaga [15], a health center in La Coruña[16] and in an emergency service in Chile [15]. Such usage proved to be reliable and valid.

Patient satisfaction has been analyzed in studies comparing surgical and medical abortion methods and different family medicine centers where abortions were performed[17]. McLemore and Wu studied the quality of abortion in the United States, identifying the issues that most concerned women via questionnaires of their own creation[18, 19].

This study aims to validate a specific tool designed based on the SERVPERF model to measure quality of care as perceived by patients who have a MA through PC.

\section{Materials And Methods}

\section{Study design}

We conducted a validation study of a Spanish adaptation of the SERVPERF scale at7 ASSIR centers of the Catalan Institute of Health in the Barcelona North Metropolitan health area, which has an assigned population of 341,511 women. The target population was women aged 16-49 years old who requested a MA. Patients were excluded from the study if they were not proficient in Spanish, exceeded 9 WG; opted for surgical abortion; or decided to continue the pregnancy. Patients who signed the informed consent were invited to participate in the study consecutively during 2019.

To validate a questionnaire, 5-10 participants per item [20] are needed. Assuming that the participant dropout rate could reach $10 \%$, a minimum of 290 women was required. Patients were recruited in proportion to the population attended toat each ASSIR center. 
The project was authorized by the Research Ethics Committee of the Institute for Primary Health Care Research Jordi Gol (IDIAPJGol) under code P15/109.

\section{Description and administration of the questionnaire}

A two-part questionnaire was designed [21]:

1. During patients' initial visit, sociodemographic information was collected: age, education attainment, living situation, social support, place of birth and year of arrival, employment situation, and obstetric history (number of abortions and living children). Data related to the MA process was also collected during this part of the questionnaire: gestational age, emergency contraception and use and type of contraception.

1. The second part of the questionnaire focused on the quality of the MA process. It consisted of 26 items, of which 20 were adapted from the SERVPERF scale and 6 corresponded to specific aspects of the MA process: perception of pain, intensity of bleeding, impact, and feeling judged (Table 1). 
Table 1

Items on the adapted SERVPERF questionnaire to determine the satisfaction of 289 patients who had a medical abortion

\section{Item Description}

very poor/poor/normal/good/excellent

$\begin{array}{lllll}\square & \square & \square & \square & \square \\ 1 & 2 & 3 & 4 & 5\end{array}$

P01 Qualification of the health professionals (abilities, experience, knowledge)

P02 Sense of trust transmitted by the health professionals

P03 Clarity of the information provided

P04 Kindness shown by the health professionals

P05 Interest shown by the health professionals in solving your problems during the process (questions answered, management, monitoring)

P06 Amount of time dedicated to you by the health professionals

P07 Health professionals' appearance (personal hygiene)

P08 Willingness of the administrative staff to provide immediate service

P09 Training of the administrative staff

p10 Coordination between the fields of healthcare and professional levels (primary care, sexual health, hospital)

p11 Amount of information provided about the process (documents, procedures, possible side effects)

p12 Aesthetics of the healthcare facilities

p13 Ease of the procedures/paperwork

p14 Ease of accessing the service (timetable, access to the center, parking, public transport)

p15 Amount of time until first visit

p16 Amount of time from first visit until the abortion

p17 Information provided to prevent future pregnancies (contraceptive methods)

p18 Information provided about subsequent psychological monitoring and resources

excessive/moderate/tolerable/slight/imperceptible 


\section{Item Description}

$\begin{array}{lllll}\square & \square & \square & \square & \square \\ 1 & 2 & 3 & 4 & 5\end{array}$

p19 Pain experienced during the abortion

p20 Level of anxiety experienced during the abortion

p21 Amount of bleeding during the abortion

p22 Impact of the abortion process on family relationships

p23 Impact of the abortion on your life

p24 Feeling judged by the staff

definitely not/.../absolutely

$\begin{array}{lllll}\square & \square & \square & \square & \square \\ 1 & 2 & 3 & 4 & 5\end{array}$

p25 Would you return to the same health center if necessary?

p26 If your friend were in the same situation, would you recommend a medical abortion?

Responses were ordinal, scored on a scale of 1-5 and included drawings of faces for easy interpretation. Items 1-18 focused on the care received. Items 19-24 addressed how the respondent was affected by the process, and items 25 and 26 asked whether they would recommend this method of abortion (Table 1) [21].

The questionnaire was given to patients to complete on their own after the MA, at the last visit of the process.

\section{Questionnaire validation}

For the descriptive analysis, the qualitative variables were summarized with their absolute and relative frequencies, and the continuous variables with their mean and standard deviation.

\section{Viability}

A pilot test was carried out to detect problems related to item comprehension, the Likert scale and any logistical issues with the study. It was performed on 24 patients, three by ASSIR centers. The mean response time for the questionnaire was 15 minutes.

After reviewing the results, the definitive questionnaire was designed on paper and later digitized using an optical reader (Teleform $®$ ). 


\section{Metric characteristics}

Lost records, floor and ceiling effects, and minimum and maximum response scores were summarized for each item.

\section{Content validity}

To formulate the questions of the adapted questionnaire, eight external experts were consulted, including gynecologists, midwives, and administrative staff. This group of experts suggested adding two items to assess the information provided to prevent future pregnancies and subsequent psychological monitoring and resources. The difficulty of assessing the presentation and physical appearance of the staff items was also discussed. They were combined into a single item called "appearance (personal hygiene)"so as to avoid assessing fashion choices, hairstyle, etc. The items "interest" and "willingness to solve..." were also combined into a single item as they were considered repetitive. The item "feeling judged by the staff" was added to address the ethical connotation of abortion. Lastly, the question "would you recommend this healthcare to a friend?" was changed to "would you recommend a medical abortion?" to switch the focus to the abortion method and avoid referring to abortion as a decision, so as not to broach ethical judgments.

\section{Construct validity}

A factorial analysis with Varimax rotation was performed to determine the dimensions in which the items were grouped. The Kaiser criterion with a saturation value $>1$ was used to identify the factors (dimensions) and explained variance. Saturation values $>0.40$ were considered for each factor. The internal consistency of each resulting dimension was analyzed (Cronbach's alpha).

\section{Reliability}

The internal consistency of the questionnaire was assessed with Cronbach's alpha value and test-retest agreement with the linearly weighted Kappa coefficient.

\section{Results}

\section{Description of the participants}

A total of 376 women were recruited, of which 354 continued with the MA process; 65 were removed for presenting exclusion criteria; 289 patients completed the study, while 44 (13.2\%) dropped out (figure 1).

The mean age of participants was 29.5 (SD7.3, range 16-45) and mean gestational age was 6.3 weeks (SD 1.1); 78.7\% had completed compulsory secondary education or high school/vocational school. Most participants were from Europe (70.5\%), followed by Central and South America (23.2\%); $74.4 \%$ had a paid job; $86.9 \%$ lived with their partner or family and $13.1 \%$ lived alone or in a shared flat. Social support was provided by participants' partners (68.2\%), followed by family $(51.3 \%)$, and $4.9 \%$ reported not having social support. (Table2) 
Table 2

Sociodemographic characteristics of study participants and dropouts

\begin{tabular}{|c|c|c|c|}
\hline Variable & $\begin{array}{l}\text { Dropouts } \\
(n=44)\end{array}$ & $\begin{array}{l}\text { Participants } \\
(n=289)\end{array}$ & p \\
\hline Age & $29.07(10.0)$ & $29.5(7.3)$ & 0.740 \\
\hline Gestational age & $6.25(1.1)$ & $6.28(1.1)$ & 0.861 \\
\hline Education attainment & & & 0.316 \\
\hline No studies or incomplete & $2(4.5 \%)$ & $11(3.8 \%)$ & \\
\hline Compulsory education & $8(18.2 \%)$ & $91(31.7 \%)$ & \\
\hline High school/vocational school & $26(59.1 \%)$ & $135(47.0 \%)$ & \\
\hline University & $8(18.2 \%)$ & $50(17.4 \%)$ & \\
\hline Place of birth & & & 0.285 \\
\hline Europe (including Spain) & $27(61.4 \%)$ & $201(70.5 \%)$ & \\
\hline Central and South America & $15(34.1 \%)$ & $66(23.2 \%)$ & \\
\hline Morocco and the rest of Africa & $2(4.5 \%)$ & $18(6.3 \%)$ & \\
\hline Paid employment & $22(66.7 \%)$ & $189(74.4 \%)$ & 0.343 \\
\hline Living situation & & & 0.662 \\
\hline Alone & $6(14.0 \%)$ & $23(8.1 \%)$ & \\
\hline With partner & $113(30.2 \%)$ & $93(32.7 \%)$ & \\
\hline With family & $22(51.2 \%)$ & $154(54.2 \%)$ & \\
\hline In a shared flat & $2(4.7 \%)$ & $14(4.9 \%)$ & \\
\hline \multicolumn{4}{|l|}{ Social support } \\
\hline Partner & $24(57.1 \%)$ & $187(68.2 \%)$ & 0.165 \\
\hline Family & $24(57.1 \%)$ & $138(51.3 \%)$ & 0.481 \\
\hline Friends & $15(35.7 \%)$ & $70(26.1 \%)$ & 0.195 \\
\hline No social support & $4(9.5 \%)$ & $13(4.9 \%)$ & 0.219 \\
\hline Number of previous abortions & & & 0.781 \\
\hline 0 & $25(56.8 \%)$ & $154(54.4 \%)$ & \\
\hline 1 & $12(27.3 \%)$ & $71(25.1 \%)$ & \\
\hline 2 & $3(6.8 \%)$ & $34(12.0 \%)$ & \\
\hline
\end{tabular}




\begin{tabular}{|llll|}
\hline Variable & $\begin{array}{l}\text { Dropouts } \\
(\mathbf{n = 4 4 )}\end{array}$ & $\begin{array}{l}\text { Participants } \\
(\mathbf{n = 2 8 9})\end{array}$ & $\mathbf{p}$ \\
\hline 3 & $2(4.5 \%)$ & $17(6.0 \%)$ & \\
\hline$\geq 4$ & $2(4.5 \%)$ & $7(2.5 \%)$ & \\
\hline Number of living children & & & 0.998 \\
\hline None & $22(50.0 \%)$ & $139(49.1 \%)$ & \\
\hline 1 & $10(22.7 \%)$ & $67(23.7 \%)$ & \\
\hline 2 & $9(20.5 \%)$ & $60(21.2 \%)$ & \\
\hline 3 & $2(4.5 \%)$ & $10(3.5 \%)$ & \\
\hline$\geq 4$ & $1(2.3 \%)$ & $7(2.5 \%)$ & \\
\hline Use of contraception & $27(64.3 \%)$ & $162(58.9 \%)$ & 0.508 \\
\hline Type of contraception & & & $<0.001$ \\
\hline Condom & $14(51.9 \%)$ & $110(67.9 \%)$ & \\
\hline Hormonal & $8(29.6 \%)$ & $52(32.1 \%)$ & \\
\hline IUD & $3(11.1 \%)$ & 0 & 0.537 \\
\hline Emergency contraception & $2(7.4 \%)$ & $26(10.2 \%)$ & \\
\hline
\end{tabular}

As for previous abortions, $45.6 \%$ of participants reported having had one or more; $49.1 \%$ did not have children; $58.9 \%$ reported using some method of contraception and $10.2 \%$ used the emergency contraceptive pill in that cycle. The condom was the most commonly used method (67.9\%), followed by hormonal contraception (32.1\%).

Patients who dropped out did not present significant differences, except for lower condom use (51.9\% vs $67.9 \%)$ and greater use of hormonal methods or IUDs (40.7\%).

\section{Questionnaire validation}

The instrument presented the full range of potential responses to the items and non-response did not exceed $2.1 \%$ for any item. The floor effect was very low (0.3-26\%); the ceiling effect was higher but did not exceed $83 \%$. (Table 3 ) 
Table 3

Description of the responses for each questionnaire item

\begin{tabular}{|c|c|c|c|c|c|}
\hline Item & (Min.-Max.) & Floor Effect & Ceiling Effect & Missing records & Mean (SD) \\
\hline $\mathrm{p} 1$ & $(3-5)$ & $13(4.5 \%)$ & 206 (71.3\%) & $4(1.4 \%)$ & $4.7(0.56)$ \\
\hline p2 & $(2-5)$ & $3(1.0 \%)$ & $217(75.1 \%)$ & $0(0.0 \%)$ & $4.7(0.61)$ \\
\hline p3 & $(2-5)$ & $2(0.7 \%)$ & $216(74.7 \%)$ & $2(0.7 \%)$ & $4.7(0.55)$ \\
\hline p4 & $(2-5)$ & $3(1.0 \%)$ & $228(78.9 \%)$ & $2(0.7 \%)$ & $4.7(0.59)$ \\
\hline p5 & $(2-5)$ & $2(0.7 \%)$ & $211(73.0 \%)$ & $0(0.0 \%)$ & $4.7(0.57)$ \\
\hline p6 & $(2-5)$ & $2(0.7 \%)$ & $176(60.9 \%)$ & $1(0.3 \%)$ & $4.6(0.62)$ \\
\hline p7 & $(3-5)$ & $7(2.4 \%)$ & $228(78.9 \%)$ & $6(2.1 \%)$ & $4.8(0.47)$ \\
\hline p8 & $(1-5)$ & $1(0.3 \%)$ & 170 (58.8\%) & $1(0.3 \%)$ & $4.4(0.79)$ \\
\hline p9 & $(1-5)$ & $2(0.7 \%)$ & 156 (54.0\%) & $2(0.7 \%)$ & $4.4(0.79)$ \\
\hline p10 & $(2-5)$ & $4(1.4 \%)$ & $144(49.8 \%)$ & $2(0.7 \%)$ & $4.4(0.75)$ \\
\hline p11 & $(2-5)$ & $3(1.0 \%)$ & 205 (70.9\%) & $0(0.0 \%)$ & $4.6(0.62)$ \\
\hline p12 & $(2-5)$ & $6(2.1 \%)$ & $117(40.5 \%)$ & $2(0.7 \%)$ & $4.2(0.80)$ \\
\hline p13 & $(3-5)$ & 27 (9.3\%) & $182(63.0 \%)$ & $1(0.3 \%)$ & $4.5(0.66)$ \\
\hline p14 & $(1-5)$ & $2(0.7 \%)$ & $136(47.1 \%)$ & $1(0.3 \%)$ & $4.2(0.86)$ \\
\hline p15 & $(1-5)$ & $1(0.3 \%)$ & $148(51.2 \%)$ & $1(0.3 \%)$ & $4.3(0.81)$ \\
\hline p16 & $(1-5)$ & $3(1.0 \%)$ & $151(52.2 \%)$ & $2(0.7 \%)$ & $4.3(0.87)$ \\
\hline p17 & $(1-5)$ & $1(0.3 \%)$ & $194(67.1 \%)$ & $1(0.3 \%)$ & $4.6(0.67)$ \\
\hline p18 & $(1-5)$ & $2(0.7 \%)$ & 149 (51.6\%) & $1(0.3 \%)$ & $4.3(0.85)$ \\
\hline p19 & $(1-5)$ & $63(21.8 \%)$ & $25(8.7 \%)$ & $3(1.0 \%)$ & $2.6(1.21)$ \\
\hline p20 & $(1-5)$ & $34(11.8 \%)$ & 38 (13.1\%) & $4(1.4 \%)$ & $3.0(1.22)$ \\
\hline p21 & $(1-5)$ & 75 (26.0\%) & 7 (2.4\%) & $3(1.0 \%)$ & $2.2(0.98)$ \\
\hline p22 & $(1-5)$ & 15 (5.2\%) & 96 (33.2\%) & $5(1.7 \%)$ & $3.6(1.23)$ \\
\hline p23 & $(1-5)$ & $20(6.9 \%)$ & $61(21.1 \%)$ & $6(2.1 \%)$ & $3.3(1.22)$ \\
\hline p24 & $(1-5)$ & $8(2.8 \%)$ & 219 (75.8\%) & $6(2.1 \%)$ & $4.6(0.92)$ \\
\hline p25 & $(1-5)$ & $2(0.7 \%)$ & 241 (83.4\%) & $2(0.7 \%)$ & $4.8(0.58)$ \\
\hline p26 & $(1-5)$ & $5(1.7 \%)$ & 205 (70.9\%) & $3(1.0 \%)$ & $4.5(0.90)$ \\
\hline
\end{tabular}

Min.-Max.: Minimum and maximum values obtained for each item; SD: Standard deviation 
All items had a mean score of over 4 points, except items 19 to 23 , which ranged from 2 to 4 points.

To determine test-retest reliability, 53 women answered the questionnaire a second time 15 to 21 days later. The linearly weighted Kappa coefficient was good to excellent in general, moderate for items 6, 8 and 11, and low for item 17. (Table 4) 
Table 4

Linearly weighted Kappa coefficient to evaluate intraobserver agreement (testretest) for each item and overall

\begin{tabular}{|lll|}
\hline Item & Linearly weighted Kappa coefficient $(\mathbf{C l} 95 \%)$ & $\mathbf{P}$ \\
\hline P01 & (N=53) & \\
\hline P02 & $0.715(0.52-0.91)$ & 0.000 \\
\hline P03 & $0.810(0.50-0.92)$ & 0.000 \\
\hline P04 & $0.744(0.56-0.95)$ & 0.000 \\
\hline P05 & $0.691(0.52-0.86)$ & 0.000 \\
\hline P06 & $0.480(0.28-0.68)$ & 0.000 \\
\hline P07 & $0.627(0.42-0.83)$ & 0.000 \\
\hline P08 & $0.413(0.19-0.64)$ & 0.000 \\
\hline P09 & $0.756(0.61-0.90)$ & 0.000 \\
\hline P10 & $0.657(0.50-0.81)$ & 0.000 \\
\hline P11 & $0.460(0.25-0.67)$ & 0.000 \\
\hline P12 & $0.655(0.51-0.80)$ & 0.000 \\
\hline P13 & $0.567(0.35-0.78)$ & 0.000 \\
\hline P14 & $0.572(0.37-0.78)$ & 0.000 \\
\hline P15 & $0.549(0.34-0.76)$ & 0.000 \\
\hline P16 & $0.662(0.48-0.85)$ & 0.000 \\
\hline P17 & $0.398(0.14-0.65)$ & 0.000 \\
\hline P18 & $0.555(0.34-0.77)$ & 0.000 \\
\hline P19 & $0.612(0.44-0.79)$ & 0.000 \\
\hline P20 & $0.514(0.32-0.71)$ & 0.000 \\
\hline P21 & $0.644(0.47-0.82)$ & 0.000 \\
\hline P22 & $0.594(0.43-0.76)$ & 0.000 \\
\hline P23 & $0.674(0.52-0.82)$ & 0.000 \\
\hline P24 & $0.639(0.40-0.87)$ & 0.000 \\
\hline P25 & $0.612(0.33-0.89)$ & 0.000 \\
\hline
\end{tabular}




\begin{tabular}{|lll|}
\hline Item & $\begin{array}{l}\text { Linearly weighted Kappa coefficient (Cl 95\%) } \\
(\mathbf{N}=53)\end{array}$ & $\mathbf{p}$ \\
\hline P26 & $0.576(0.34-0.82)$ & 0.000 \\
\hline Overall & $0.681(0.64-0.72)$ & 0.020 \\
\hline
\end{tabular}

Cl 95\%: Confidence interval 95\%

\section{Questionnaire dimensions.}

An exploratory factor analysis was performed with Varimax rotation, obtaining a total of 7 dimensions that explain $65.9 \%$ of variability. (Table 5 ) 
Table 5

Component matrix with varimax rotation of the 26 items from the adapted SERVPERF questionnaire Factorial coefficients of the items after rotation

\begin{tabular}{llllllll|}
\hline Item & F1 & F2 & F3 & F4 & F5 & F6 & F7 \\
p01 & 0.696 & 0.225 & 0.186 & 0.200 & 0.030 & 0.085 & -0.074 \\
\hline p02 & 0.846 & 0.102 & 0.131 & 0.122 & 0.080 & -0.016 & 0.015 \\
\hline p03 & 0.593 & 0.262 & -0.106 & 0.418 & 0.096 & -0.002 & 0.270 \\
\hline p04 & 0.832 & 0.138 & 0.093 & 0.086 & 0.018 & -0.017 & 0.114 \\
\hline p05 & 0.758 & 0.225 & 0.119 & 0.107 & -0.071 & 0.060 & 0.122 \\
\hline p06 & 0.572 & 0.155 & 0.448 & 0.292 & -0.003 & -0.016 & -0.001 \\
\hline p07 & 0.584 & 0.247 & 0.257 & 0.255 & -0.120 & -0.015 & 0.092 \\
\hline p08 & 0.245 & 0.828 & 0.145 & 0.003 & 0.050 & 0.053 & 0.022 \\
\hline p09 & 0.135 & 0.838 & 0.194 & 0.139 & 0.048 & 0.094 & -0.008 \\
\hline p10 & 0.262 & 0.715 & 0.153 & 0.254 & -0.005 & 0.000 & 0.040 \\
\hline p11 & 0.302 & 0.283 & 0.036 & 0.617 & 0.172 & -0.064 & 0.219 \\
\hline p12 & 0.329 & 0.460 & 0.337 & 0.086 & 0.020 & -0.002 & -0.062 \\
\hline p13 & 0.363 & 0.453 & 0.296 & 0.181 & 0.077 & -0.108 & 0.228 \\
\hline p14 & 0.086 & 0.330 & 0.530 & 0.187 & 0.112 & -0.014 & 0.187 \\
\hline p15 & 0.091 & 0.263 & 0.792 & 0.080 & 0.046 & 0.057 & 0.021 \\
\hline p16 & 0.254 & 0.109 & 0.722 & 0.083 & 0.006 & 0.100 & 0.191 \\
\hline p17 & 0.397 & 0.109 & 0.361 & 0.579 & -0.018 & 0.054 & -0.103 \\
\hline p18 & 0.263 & 0.202 & 0.255 & 0.659 & 0.077 & 0.146 & -0.046 \\
\hline p19 & -0.037 & 0.074 & -0.048 & 0.195 & 0.101 & 0.785 & 0.046 \\
\hline p20 & 0.050 & 0.033 & 0.027 & 0.083 & 0.431 & 0.679 & 0.122 \\
\hline p21 & -0.012 & 0.126 & -0.133 & -0.030 & 0.731 & -0.040 \\
\hline p22 & 0.042 & 0.076 & 0.152 & 0.879 & 0.010 & -0.047 \\
\hline & & & & & & \\
\hline
\end{tabular}

Extraction method: Principal Component Analysis

Rotation method: Varimax normalization. The Kaiser criterion was used with an Eigenvalue $>1$ to determine the resulting factors and explained variance (65.9\%). In each dimension, those items that presented a saturation value $>0.40$ 


\section{Factorial coefficients of the items after rotation}

$\begin{array}{llllllll}\text { p23 } & 0.029 & 0.042 & 0.041 & -0.022 & 0.806 & 0.305 & -0.024 \\ \text { p24 } & 0.531 & 0.142 & -0.092 & -0.354 & 0.368 & -0.158 & 0.161 \\ \text { p25 } & 0.248 & 0.098 & 0.129 & 0.014 & -0.105 & 0.017 & 0.780 \\ \text { p26 } & -0.018 & -0.041 & 0.104 & 0.017 & 0.045 & 0.059 & 0.809 \\ \text { Eigenvalues } & 8.088 & 2.379 & 1.743 & 1.482 & 1.332 & 1.104 & 1.008\end{array}$

Extraction method: Principal Component Analysis

Rotation method: Varimax normalization. The Kaiser criterion was used with an Eigenvalue $>1$ to determine the resulting factors and explained variance (65.9\%). In each dimension, those items that presented a saturation value $>0.40$

Table 5 presents the factorial coefficients of the component matrix with Varimax rotation of the 26 items and Table 6 shows the dimensions in which the items are grouped, as well as the internal consistency values (Cronbach's alpha) for all items (0.862) and each dimension. All the items initially proposed for each dimension were maintained except for item 12, which was transferred from dimension 2 to 3 as this was a better conceptual fit. The decision was upheld because the alpha coefficients of dimensions 2 and 3 did not undergo significant changes ( 0.834 to 0.824 and 0.724 to 0.727 , respectively).

Table 6

Dimensions resulting from the factor analysis, their internal consistency and list of associated items

\begin{tabular}{|lllll|}
\hline Dimensions & Description & $\begin{array}{l}\text { Cronbach's } \\
\text { alpha }\end{array}$ & $\begin{array}{l}\text { Number of } \\
\text { items }\end{array}$ & $\begin{array}{l}\text { Associated } \\
\text { items }\end{array}$ \\
\hline 1 & Health professionals & 0.861 & 8 & $1,2,3,4,5,6,7$, \\
\hline 2 & Administrative staff & 0.824 & 4 & $8,9,10,13$ \\
\hline 3 & Organization management & 0.727 & 4 & $12,14,15,16$ \\
\hline 4 & Information provided & 0.737 & 3 & $11,17,18$ \\
\hline 5 & $\begin{array}{l}\text { Clinical aspects of the } \\
\text { process }\end{array}$ & 0.676 & 3 & $19,20,21$ \\
\hline 6 & Impact of the process & 0.749 & 2 & 22,23 \\
\hline 7 & Satisfaction process & 0.598 & 2 & 25,26 \\
\hline Overall & & 0.862 & 26 & $1-26$ \\
\hline
\end{tabular}


In general, the internal consistency obtained for each dimension shows acceptable or good values, except for dimensions 5 and 7 , in which it was somewhat low.

Thus, 5 dimensions similar to those of the SERVPERF scale were obtained, corresponding to healthcare personnel and administrative staff, management or tangible dimension, information and impact of the process, clinical aspects of the process (including pain, bleeding and anxiety), and satisfaction with the process, (would the patient recommend the process to a friend, would the patient come back if necessary). These last two dimensions, which were specific to the MA process, obtained the lowest internal consistency scores.

\section{Discussion}

The results of the validation process of the adapted SERVPERF scale present a valid instrument for measuring satisfaction and quality of service in patients who request a MA.

The sociodemographic characteristics of the participants are similar to those of the population in Catalonia that requests a MA, according to the 2018 statistics reported by the Department of Health [5]. The most relevant difference is that $42 \%$ of patients were locals in the reported statistics, while in our study $66.3 \%$ were. This is most likely explained by having included improficiency in Spanish as an exclusion criterion.

Prior to this study, the effectiveness of the MA process had already been demonstrated and supported by protocols [5], but no data had been collected on quality as perceived by patients. In 2019, the first article on a validated, person-centered abortion care scale was published in Kenya [22]. The lack of data on the quality of abortion care may be due to the highly stigmatized status of the procedure.

McLemore assessed the experience of the outpatient abortion process in the United States: $70 \%$ of patients reported having had a better experience than expected; the rest mentioned the need to improve pain management and waiting time [18]. These findings support the decision to include 5 items related to the MA process in our proposal.

Sudhinaraset et al in 2020 published a validation of a person-centered abortion scale, in private care, both surgical and medical, in a restrictive legal context of abortion[23]. The dimensions of respectful care and communication predominated. Our scale also assesses the organization, the clinical aspects and the impact of the process. They assessed that these types of scales can be adapted for different sexual and reproductive health services.

Baynes studied how women experience post-MA visits in Tanzania [24]. Although the women were satisfied with the privacy and proximity of care, they identified significant areas for improvement: office cleanliness, post-contraception counseling, and pain management. In our study, the quality of these aspects was assessed as good. The scale presents good metric characteristics since it does not show 
saturated floor or ceiling effects and there was a high response rate for all items. The non-response rates for items 22-24 might be due to their placement on the back page of the questionnaire [21].

In general, the scores were high for all items, except for 19-23, which were related to the MA process. This is consistent with other studies in which items related to pain management, bleeding, and anxiety during the process scored lower[17, 18].

In the factor analysis, 7 dimensions were obtained that explain a total variance of $65.9 \%$, similar to that obtained by Gómez-Besteiro (69.3\%)[16].

The items added to address the process were grouped into two specific dimensions, which was deemed coherent.

In general, item agreement was moderate to excellent, except for items 6,8 and 11 , for which it was moderate, likely due to a certain degree of subjectivity. Predisposition, time dedicated and sufficient information may be perceived differently depending on patients' need for support.

Item 17,which asked about the information provided to prevent unwanted pregnancies in the future, showed low reliability. This was also observed in the Baynes study as an aspect to be improved [24]. One solution would be to provide this information at the end of the process along with free contraception.

The dimensions obtained are similar to those proposed in other SERVPERF validation processes for healthcare. Gómez-Besteiro obtained the same 5 dimensions but distinguished between medical and nursing staff[16]. In our study, the healthcare professionals dimension included gynecologists and midwives since both are involved in the process. Torres obtained 7 dimensions, including safety[25], which has already been analyzed in our area[5].

As for the limitations of this study, the important ethical-moral connotation of MAs must be considered. Although it is currently legal, it is still an ethical conflict. This factor may have influenced the number of study dropouts.

After performing the MA, some women did not attend follow-up visits. However, the dropout rate was low $(13.2 \%)$ and no differences were observed that would suggest the existence of any type of risk.

\section{Conclusions}

The results of this study provide a valid and reliable instrument for measuring the perception of quality in the service of users of a MA. With 26 items and a filling time of about 15 minutes, it makes it a useful and feasible tool for the continuous improvement of the service.

This scale is the best tool to assess and improve the quality of the MA service, with a view towards excellence in the sphere of public health. 


\section{List Of Abbreviations}

MA: Medical Abortion

WG:Weeks Gestation

ASSIR: Sexual and Reproductive Health Care Centers

PC: Primary Care

WHO: World Health Organization

PLAENSA: Satisfaction survey plan

SERVPERF: SERVice-PERFormance

IDIAP JGol: Foundation University Institute for Primary Health Care Research Jordi Gol i Gurina

TeleForm: OpenText TeleForm, Data Capture Software

\section{Declarations}

\section{Ethics approval and consent to participate}

The participants were informed of the project and signed their informed consent

This study was conducted according to the guidelines of the Declaration of Helsinki and was authorized by the Research Ethics Committee of the Institute for Primary Health Care Research Jordi Gol (IDIAPJGol) under code P15/109.

\section{Consent for publication}

'Not applicable' for that section.

\section{Availability of data and materials}

The data for the analysis, the questionnaires used and other supplementary material are available in Mendeley Data [21], http://dx.doi.org/10.17632/45jz576dny.4

\section{Competing interests}

The authors declare that they have no competing interests.

\section{Funding}


This project has received "Fourth Research Award from the Catalan Association of Midwifes", with funding to be published

\section{Authors' contributions}

All authors have made substantial contributions to the manuscript. RC, MMH, JM, MM, AR, LM have contributed to the conception or design of the work. JM, GF, RC have performed the analysis and interpretation of data; $\mathrm{RC}, \mathrm{JM}, \mathrm{MMH}, \mathrm{LM}$ have contributed in the writing and preparation of the present manuscript. All authors substantively revised it.

All authors have approved the submitted version (and any substantially modified version that involves the author's contribution to the study)

All authors have agreed both to be personally accountable for the author's own contributions and to ensure that questions related to the accuracy or integrity of any part of the work, even ones in which the author was not personally involved, are appropriately investigated, resolved, and the resolution documented in the literature.

\section{Acknowledgements}

We appreciate the collaboration for the recruitment of patients and obtaining the survey provided by the professionals of the Sexual and Reproductive Health Care Centers (ASSIR) of the Primary Care (PC) service:

Ahinoa Borràs Reventer, Alba Llobera Sanz, Ana Andrade Poveda, Anna Estruch Riu, Anna Vila Corominas, Carme Puig Barat, Carmen Barrionuevo Ramirez, Carolina Fernández Monteagudo, Celia Ortega Cejas, Cristian Rios Gozalvez, Dolores Cruz Panadero, Encarna Viciana Castro, Ester Duran Arbonés, Ester Muñoz Sellés, Esther Cerro Hernandez, Fina Martinez Juan, Gemma Hernandez Esteruelas, Hildegard Mausbach, Imma Cots Paltor, Immaculada-Concepció Trujillo Pintor, Ingrid Navarro Alonso, Inma Hisado García, Inmaculada Torruella Martinez, Irene Fernandez Varela, Isabel Rosa Trinidad, Isabel San Nicolas Gomez, Judit Laso Cozar, Judit Tarrés Rovira, Kelly Alida López Ponce, Laura Aznar López, Laura Cánovas Mira, Loira Ocaña Cruz, Lorena Serrano Martín, Lucia Burgos Cubero, Ma Ángeles Jiménez Pedroche, $\mathrm{M}^{\mathrm{a}}$ Carmen Vidal Testal, $\mathrm{M}^{\mathrm{a}}$ Dolores Gomez Merino, Margalida Colldeforns Vidal, Maria Cejas Maldonado, Maria del Carmen Basset Ausas, Maria Gonzalez Hernández, Marta Cámara Cámara, , Maria Jose Ayuso Campos, Maria Nadales Borras, Mercè Cuerda Cusine, Meritxell Gomez Maldonado, Mireia Rojas Torrijos, Mónica Gallardo Gutiérrez, Mònica Martínez Garcia, Montse Manzanares Miguel, Montse Martínez Rodríguez, Nieves Guerrero Martinez, Núria Armengol Bosch, Núria Vilanova Alsedà, Raquel Moreno Iglesias, Remei Fenollosa Pérez, Rosa Díaz Gallardo, Saray González Pérez, Silvia Corchs Cutura, Silvia Palmero Aliste, Sònia Maireles Membrado.

\section{References}


1. Idescat. Interrupció voluntària de l'embaràs. Anuari estadístic de Catalunya. 2018. https://www.idescat.cat/pub/?id=aec\&n=823. Accessed 4 Feb 2020.

2. Ministerio de Sanidad Consumo y Bienestar Social. Interrupciones Voluntarias del Embarazo. Plan Estadístico Nacional de España. 2018.

https://www.mscbs.gob.es/profesionales/saludPublica/prevPromocion/embarazo/home.htm. Accessed 4 Feb 2020.

3. Boletin Oficial del Estado. Ley Orgánica 2/2010, de 3 de marzo, de salud sexual y reproductiva y de la interrupción voluntaria del embarazo (BOE-A-2010-3514). Madrid; 2010. https://www.boe.es/buscar/pdf/2010/BOE-A-2010-3514-consolidado.pdf.

4. World Health Organization. Medical management of abortion. Geneve; 2018. http://apps.who.int/. Accessed 17 Dec 2020.

5. Servei de Gestió i anàlisi de la informació per a la Planificació estratègica. Estadística de la interrupció voluntària de l' embaràs a Catalunya,2018. 2019.

http://salutweb.gencat.cat/web/.content/_departament/estadistiques-sanitaries/dades-de-salutserveis-sanitaris/interrupcio-voluntaria-embaras/IVE-2018.pdf.

6. White K. Sobre Servicios De Salud: Organ Panam la Salud. 1992;:382-404. file://C:/Users/JMMan/Downloads/Investigaciones sobre servicios de salud una antologia (1).pdf.

7. Departament de Salut. Generalitat de Catalunya. Pla de Salut de Catalunya 2016-2020. 2016. http://salutweb.gencat.cat/web/.content/_departament/pla-de-salut/Pla-de-salut-20162020/documents/Pla_salut_Catalunya_2016_2020.pdf.

8. Bigné E, Moliner MA, Sánchez J. Perceived quality and satisfaction in multiservice organisations: the case of Spanish public services. J Serv Mark. 2003;17:420-42. doi:10.1108/08876040310482801.

9. Parasuraman AA, Zeithaml VA, Berry LL. Refinement and reassessment of the SERVQUAL instrument. J Retail. 1991;67:420-50.

10. Cronin JJ, Taylor SA. SERVPERF versus SERVQUAL: Reconciling Performance-Based and Perceptions-Minus-Expectations Measurement of Service Quality. J Mark. 1994;58:125.

11. Ibarra Morales LE, Casas Medina EV. Aplicación del modelo Servperf en los centros de atención Telcel, Hermosillo: Una medición de la calidad en el servicio. Contaduria y Adm. 2015;60:229-60. doi:10.1016/S0186-1042(15)72153-4.

12. Naranjo Martinez FA. Aplicacion del modelo servperf para medir la calidad del servicio entre la organizacion y el cliente industrial. Universidfad Nacional de Colombia; 2013. http://www.bdigital.unal.edu.co/45807/.

13. Duque Oliva EJ, Canas Baquero JA. Validación del modelo SERVPERF en el ámbito de internet: un caso colombiano - Validation of the SERVPERF model in the internet environment: a Colombian case. Suma Negocios. 2014;5:115-23.

14. Shafei I, Walburg J, Taher A. Verifying alternative measures of healthcare service quality. Int J Health Care Qual Assur. 2016;32:516-33. doi:10.1108/IJHCQA-05-2016-0069.

15. Díaz R. La calidad percibida en la sanidad pública. Rev Calid Asist. 2005;20:35-42. 
16. Gómez-Besteiro MI, Somoza-Digón J, Einöder-Moreno M, Jiménez-Fraga MN, Castiñeira-Pereira S, Feijoo-Fuentes ML. Calidad de atención en salud percibida por los pacientes en un centro de salud urbano de A Coruña. Enferm Clin. 2012;22:182-90.

17. Rørbye C, Nørgaard M, Nilas L. Medical versus surgical abortion: Comparing satisfaction and potential confounders in a partly randomized study. Hum Reprod. 2005;20:834-8.

18. McLemore MR, Desai S, Freedman L, James EA, Taylor D. Women Know Best-Findings from a Thematic Analysis of 5,214 Surveys of Abortion Care Experience. Women's Heal Issues. 2014;24:594-9.

19. Wu JP, Godfrey EM, Prine L, Andersen KL, MacNaughton H, Gold M. Women's satisfaction with abortion care in academic family medicine centers. Fam Med. 2015;47:98-106. http://www.ncbi.nlm.nih.gov/pubmed/25646981.

20. Streiner DL, Norman GR, Cairney J. Health Measurement Scales. 2015th edition. Oxford (UK): Oxford University Press; 2015. doi:10.1093/med/9780199685219.001.0001.

21. Manresa-Domínguez J-M, Cabedo-Ferreiro R. SERVPERF Questionnaire. Mendeley data: database, questionnaire and supplementary material. 2020. doi: 10.17632/45jz576dny.4

22. Sudhinaraset $M$, Landrian A, Montagu D, Mugwanga $Z$. Is there a difference in women's experiences of care with medication vs. manual vacuum aspiration abortions? Determinants of person-centered care for abortion services. PLoS One. 2019;14:e0225333. doi:10.1371/journal.pone.0225333.

23. Sudhinaraset M, Landrian A, Afulani PA, Phillips B, Diamond-Smith N, Cotter S. Development and validation of a person-centered abortion scale: the experiences of care in private facilities in Kenya. BMC Women's Heal 2020 201. 2020;20:1-11. doi:10.1186/S12905-020-01071-W.

24. Baynes C, Yegon E, Lusiola G, Kahando R, Ngadaya E, Kahwa J. Women's Satisfaction With and Perceptions of the Quality of Postabortion Care at Public-Sector Facilities in Mainland Tanzania and in Zanzibar. Glob Heal Sci Pract. 2019;7 Supplement 2:S299-314. doi:10.9745/GHSP-D-19-00026.

25. Torres Navarro C, Jélvez Caamaño A, Vega Pinto F. Evaluación de la calidad en un servicio de urgencia utilizando el modelo servperf. Universidad, Cienc y Tecnol. 2014;18:38-49. http://ve.scielo.org/scielo.php?script=sci_arttext\&pid=S1316$48212014000200004 \&$ Ing=es\&nrm=iso. Accessed 6 Apr 2020.

\section{Figures}




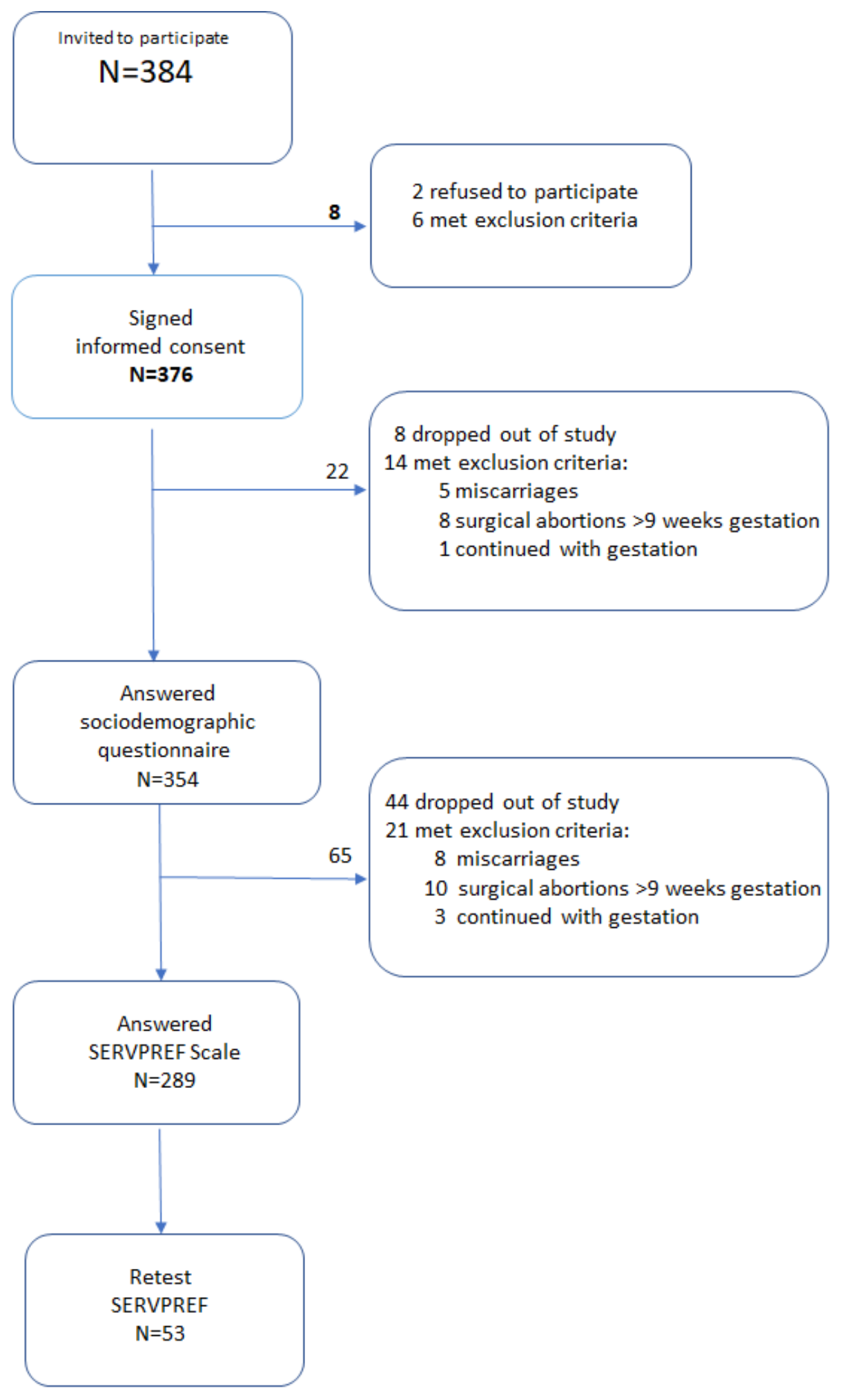

\section{Figure 1}

Participation flow chart Note: This diagram shows the flow of participants and the reasons for the loss of participants 